\section{Michigan Technological

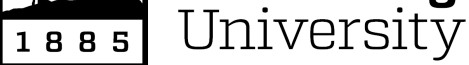

Michigan Technological University Digital Commons @ Michigan Tech

\title{
A New Method to Determine the Effects of Hydrodynamic Surface Coatings on the Snow Shedding Effectiveness of Solar Photovoltaic Modules
}

Rob W. Andrews

Queen's University - Kingston, Ontario

Andrew Pollard

Queen's University - Kingston, Ontario

Joshua M. Pearce

Michigan Technological University

Follow this and additional works at: https://digitalcommons.mtu.edu/materials_fp

\section{Recommended Citation}

Andrews, Rob. W., Pollard, Andrew, \& Pearce, Joshua M. (2013). A new method to determine the effects of hydrodynamic surface coatings on the snow shedding effectiveness of solar photovoltaic modules. Solar Energy Materials and Solar Cells, 113, 71-78. http://digitalcommons.mtu.edu/materials_fp/26 
Preprint of: Rob W. Andrews, Andrew Pollard, Joshua M. Pearce, A new method to determine the effects of hydrodynamic surface coatings on the snow shedding effectiveness of solar photovoltaic modules. Solar Energy Materials and Solar Cells 113 (2013) 7178. DOI: 10.1016/j.solmat.2013.01.032

\title{
A new method to determine the effects of hydrodynamic surface coatings on the snow shedding effectiveness of solar photovoltaic modules
}

\author{
Rob W. Andrews ${ }^{\mathrm{a}}$, Andrew Pollard ${ }^{\mathrm{a}}$, Joshua M. Pearce ${ }^{\mathrm{b}, *}$ \\ a Department of Mechanical and Materials Engineering, Queen's University, Canada \\ ${ }^{b}$ Department of Materials Science and Engineering and Department of Electrical and Computer Engineering, Michigan \\ Technological University, USA
}

\begin{abstract}
As solar photovoltaic (PV) installations have become more common in regions that experience substantial snowfall, losses in energy production due to snow coverage have grown in concern. Several post-production surface coatings have been proposed to enhance snow shedding to reduce these snow related losses. In this paper, a novel methodology is developed to determine the effectiveness of a snow clearing from a PV module and is used to evaluate the snow shedding effectiveness of any module surface treatment. Measured PV output is compared to modelled PV output in a generalizable method that allows for the determination of the length of time a panel is covered with snowfall using electrical performance data. This model accounts for module degredation during long term outdoor testing and other external factors effecting performance, such as persistent soiling losses. This methodology was tested on modules that had one of four hydrodyanmic surface coatings, as well as one module with a prismatic glass front in order to determine the snow clearing effectiveness of these surfaces as compared to conventional plain glass. The methodology was validated, but the surface coatings tested did not have an appreciable positive effect on snow clearance, and in some cases tended to impede the shedding of snow. The physical mechanisms responsible for the results are discussed.
\end{abstract} Keywords: Snow, Photovoltaics, Snow losses, Hydrodynamic, Surface Coatings, loss reduction

\section{Introduction}

Solar photovoltaic(PV) technology is becoming financially competitive in a growing number of jurisdictions worldwide [1], and government incentives for sustainable technologies are enabling PV to be competitive in regions where the technology has not yet reached grid parity with subsidized traditional generation. This has lead to the installation of $\mathrm{PV}$ in regions exposed to snowfall in the winter months, which can lead to losses in energy generated due to snow coverage [2-4]. It has been shown in the past that hydrodynamic coatings can improve the clearance of ice from glass surfaces [5-10], but no previous

*601 M and M Building 1400 Townsend Drive Houghton, MI 49931-1295 906-487-1466

Email address: pearce@mtu.edu (Joshua M. Pearce) 
Preprint of: Rob W. Andrews, Andrew Pollard, Joshua M. Pearce, A new method to determine the effects of hydrodynamic surface coatings on the snow shedding effectiveness of solar photovoltaic modules. Solar Energy Materials and Solar Cells 113 (2013) 7178. DOI: 10.1016/j.solmat.2013.01.032

methodology was successful to account for potential energy gains related to improved snow removal from PV modules due to hydrodynamic coatings. This work provides a methodology and preliminary results that investigate the effectiveness of hydrodynamic coatings and surface treatments on the clearing of snow from PV modules. The methodology presented utilizes time-series performance data and time lapse photography to identify snow clearing effectiveness of a surface coating. A concern with using this long term performance data is the uneven degradation of PV modules over a test campaign, and a method for accounting for these effects while avoiding the requirement of regular flash testing is presented.

\section{Background}

Previous work has investigated the effects of snowfall on the performance of PV systems [2, 11-16], and the results of these investigations have been summarized and expanded by the authors in recent publications $[3,4]$. From these studies it has been observed that snowfall can degrade the production of PV systems, and therefore it is desirable to investigate methods to effectively clear modules of snowfall to maximize solar electric yearly output.

The accumulation of ice on surfaces has been extensively studied mainly with the goal to reduce ice accumulation on power infrastructure, aircraft surfaces, wind turbine blades and other industrial surfaces. As such, hydrophobic and superhydrophobic coatings have been tested for their icephobic properties. Previously, the crystallization time onto a coated surface [17-20] or the shear stress required for ice detachment [5-10] have been consitered as measures of icephobicity. It was found that the contact angle (CA), which is generally used as a measure of hydrophobicity is not a reliable indicator of icephobicity. However, the contact angle hysteresis $(\mathrm{CAH})$ was found to correlate well with icephobic properties [5-7]. The CAH is defined as the difference between the advancing $\left(\theta_{a d v}\right)$ and receding $\left(\theta_{r e c}\right)$ contact angles, and is also analogous to the angle at which a stationary droplet will begin to slide $\left(\alpha_{\text {slide }}\right)$ through [21]:

$$
\frac{m g}{w} \sin \left(\alpha_{\text {slide }}\right)=\gamma_{L V}\left(\cos \left(\theta_{\text {rec }}\right)-\cos \left(\theta_{a d v}\right)\right)
$$

where $m$ is the mass of the water droplet, $w$ is the width of the drop perpendicular to the sliding direction, $g$ is the gravitational constant, and $\gamma_{L} V$ is the liquid-vapour surface tension. Further, it was noted that the dimensionless factor $\left[1+\cos \left(\theta_{\text {rec }}\right)\right]$ scales linearly with the $\mathrm{CAH}$ and can also be used as a predictor of icephobicity [10]. Thus the three terms: $\mathrm{CAH}, \alpha_{\text {slide }}$, and $\left[1+\cos \left(\theta_{\text {rec }}\right)\right]$ can be utilized as predictors of icephobicity.

The interaction of water droplets with a surface was also found to have an impact on its icephobic properties, which can be described generally by two states of wetting: the Wenzel or Cassie-Baxter state. The Wenzel state exists when water has penetrated the surface roughness of the coating, and the CassieBaxter state is observed when air is trapped between the water and asperities (roughness) of the surface 
Preprint of: Rob W. Andrews, Andrew Pollard, Joshua M. Pearce, A new method to determine the effects of hydrodynamic surface coatings on the snow shedding effectiveness of solar photovoltaic modules. Solar Energy Materials and Solar Cells 113 (2013) 7178. DOI: 10.1016/j.solmat.2013.01.032

coating and is associated with improved icephobic properties [6]. In the case of humidity or high droplet impact velocities, the state can be changed from the Cassie-Baxter to Wenzel state, which will decrease the icephobicity of the surface for a particular surface coating [7].

Surface roughness is integral to the hydrophobicity of many non-nanostructured coatings, however it has been found that through a series of freeze-clear events, the hydrophobicity of a surface will be decreased as asperities are damaged through the expansion and contraction of water in the coating [5, 7, 8]. Thus, nano-structured hydrophobic coatings are predicted to have improved icephobic performance due to their improved durability during freeze-clear cycles, and their predicted promotion of freezing in the Cassie-Baxter state $[10]$.

There has been a limited amount of work to extend the concepts of icephobicity to snow clearing effectiveness. However, it has shown that the hydrodynamic behaviour of a surface will affect the adhesion and sliding of snow in a variety of ways that depend on the water content of the snow cover. Specifically, it was found that a hydrophilic surface will tend to promote the sliding of a "wet" snow sheet, which is defined as snow above the temperature of $-1^{\circ} \mathrm{C}$ to $-2^{\circ} \mathrm{C}$ [22]. In this case the hydrophilic surface will tend to attract the water in the snow and form a lubricating water layer at the surface of the glass that promotes snow sliding. For a hydrophobic coating, the surface will tend to resist the adhesion of snow, and will not promote the forming of a water layer. Therefore, wet snow will not as easily shed from the hydrophobic surface. However, because of the lower adhesion of snow and lower surface energy of the glass, "dry" snow defined as snow formed below $-1^{\circ} \mathrm{C}$ to $-2^{\circ} \mathrm{C}$, will shed preferentially from this surface [22]. The tendency of snow to adhere to a surface has also been studied and it was shown that a hydrophobic surface will tend to decrease the likelihood of snow adhesion, whereas a hydrophilic coating will increase the probability of this adhesion [23]. For application to $\mathrm{PV}$ in regions where snow exists and the temperature varies around the $-1^{\circ}--2^{\circ}$ switch point, the determination of optimal surface properties is complicated. This paper presents a generalizable method to make this determination for any PV and surface coating.

\section{Methodology}

A test system was installed at the Open Solar Outdoors Test Field (OSOTF) in Kingston, Ontario Canada. This site was developed based on open-source principles, and consists of solar PV modules of mono- poly- crystalline silicon (c-Si) and hydrogenated amorphous silicon (a-Si:H) installed at tilt angles of $5^{\circ}, 10^{\circ}, 15^{\circ}, 20^{\circ}, 40^{\circ}$, and $60^{\circ}$ [24]. For this study sixteen c-Si modules at angles of $10^{\circ}, 20^{\circ}, 40^{\circ}$ and $60^{\circ}$ were used, with each angle consisting of four modules, with the following surface treatments: Hydrophobic, hydrophilic, prismatic glass, and one unaltered module. Nine a-Si:H modules were installed at angles of $10^{\circ}, 20^{\circ}$, and $60^{\circ}$ and each angle consited of a total of three panels with the following surface treatements: 
Preprint of: Rob W. Andrews, Andrew Pollard, Joshua M. Pearce, A new method to determine the effects of hydrodynamic surface coatings on the snow shedding effectiveness of solar photovoltaic modules. Solar Energy Materials and Solar Cells 113 (2013) 7178. DOI: 10.1016/j.solmat.2013.0rylazalline Module Coating

two hydrophobic coated modules and one unaltered module. This facility was monitored over the winters of $2010 / 2011$ and $2011 / 2012$. Table 1 shows a summary of the installed modules, and a description of the coatings and coating methodology used is provided below.

Table 1: Module index reference, $c$ represents crystalline and $a$ represents amorphous. (ho1)... (ho3) represent hydrophobic coatings, (hy) represents a hydrophyllic coating, (Prism) represents a prismatic glass front surface and (C) represents a control module.

\begin{tabular}{|c|c|c|c|}
\hline \multicolumn{2}{|c|}{ c-Si } & \multicolumn{2}{|c|}{ a-Si:H } \\
\hline $\begin{array}{l}\text { Module } \\
\text { Index- } \\
\text { technology- } \\
\text { (coating) }\end{array}$ & Module Angle & $\begin{array}{l}\text { Module } \\
\text { Index- } \\
\text { technology- } \\
\text { (coating) }\end{array}$ & Module Angle \\
\hline $1-c-(C)$ & $10^{\circ}$ & $1-a-(C)$ & $10^{\circ}$ \\
\hline 2-c-(hy) & $10^{\circ}$ & 2-a-(ho2) & $10^{\circ}$ \\
\hline 3-c-(ho1) & $10^{\circ}$ & 3-a-(ho3) & $10^{\circ}$ \\
\hline 4-c-(Prism) & $10^{\circ}$ & $4-a-(C)$ & $20^{\circ}$ \\
\hline $5-c-(C)$ & $20^{\circ}$ & 5 -a-(ho2) & $20^{\circ}$ \\
\hline 6-c-(hy) & $20^{\circ}$ & 6-a-(ho3) & $20^{\circ}$ \\
\hline 7-c-(ho1) & $20^{\circ}$ & 7-a-(C) & $40^{\circ}$ \\
\hline 8-c-(Prism) & $20^{\circ}$ & 8-a-(ho2) & $60^{\circ}$ \\
\hline $9-c-(C)$ & $40^{\circ}$ & 9 -a-(ho3) & $60^{\circ}$ \\
\hline 10-c-(hy) & $40^{\circ}$ & & \\
\hline 11-c-(ho1) & $40^{\circ}$ & & \\
\hline 12-c-(Prism) & $40^{\circ}$ & & \\
\hline $13-c-(C)$ & $60^{\circ}$ & & \\
\hline 14-c-(hy) & $60^{\circ}$ & & \\
\hline 15-c-(Prism) & $60^{\circ}$ & & \\
\hline
\end{tabular}

\subsection{Crystalline Module Coating}

The coatings used on the c-Si modules were nano-structured, bonded covalently to the surface of the glass, and formed a layer 10-30 $\mathrm{nm}$ in thickness. The modules were first cleaned using a commercially available window cleaner. The coating was then applied evenly over the surface of the module using an application wand, and was then buffed into the glass surface using a microfibre cloth. Modules coated with the hydrophobic (ho1) treatment were then rinsed to remove excess solvent. The hydrophyllic (hy) coating was cleaned using the same commercially available window cleaner to remove excess solvent. 
Preprint of: Rob W. Andrews, Andrew Pollard, Joshua M. Pearce, A new method to determine the effects of hydrodynamic surface coatings on the snow shedding effectiveness of solar photovoltaic modules. Solar Energy Materials and Solar Cells 113 (2013) 7178. DOI: 10.1016/j.solmat322)13Anh.032hous module coatings

\subsubsection{Prismatic Glass}

Commercially available framed c-Si modules with a primsmatic stipple glass front sheet were installed in the test system. The dimensions of the surface structure are shown in an optical microscope image in Figure 1.

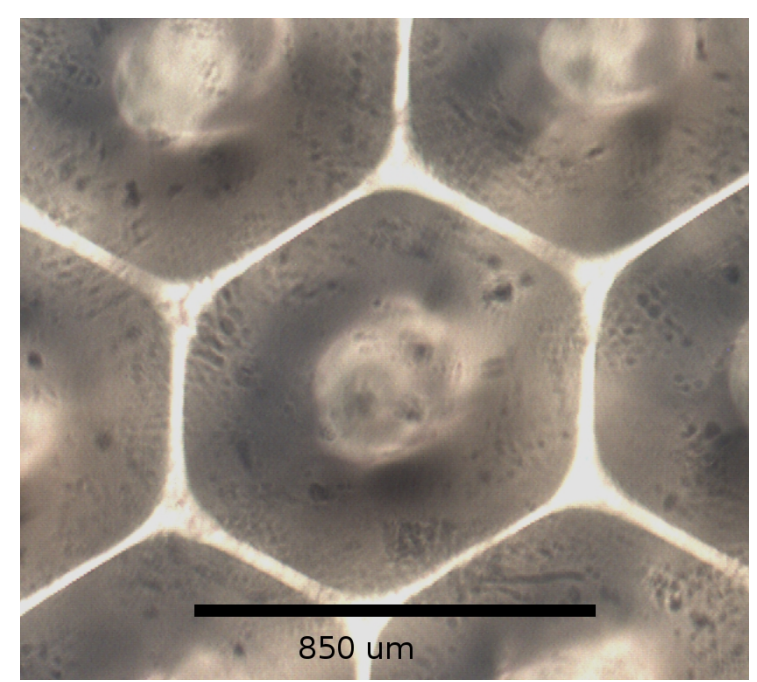

Figure 1: Optical microscope image normal to prismatic glass formation, showing $850 \mu m$ formations

\subsection{Amorphous module coatings}

All the coatings utilized in this study were applied manually after module production to new, nondegraded modules. As shipped, the a-Si:H modules had a visible glue residue on the glass front face from the manufacturer. Therefore, an abrasive solvent was used to clean the residue from the front of the modules, and this would have removed any existing coatings on the glass in the process.

\subsubsection{Coating ho2}

Coating ho2 is a fluorinated hydrophobic coating, and was manually buffed onto the entire module surface using a microfibre cloth at room temperature $\left(22^{\circ} \mathrm{C}\right)$.

\subsubsection{Coating ho3}

Coating ho3 is a hydrophobic coating of an unknown composition utilized as a commercial rain shedding coating for wind shields. The coating was applied as a spray, which was buffed into the surface of the glass using a microfibre cloth until all solvent had evaporated. 
Preprint of: Rob W. Andrews, Andrew Pollard, Joshua M. Pearce, A new method to determine the effects of hydrodynamic surface coatings on the snow shedding effectiveness of solar photovoltaic modules. Solar Energy Materials and Solar Cells 113 (2013) 7178. DOI: 10.1016/j.solmat.2013.01.032 3.3 Scatterometry

\subsection{Scatterometry}

The surfaces were characterized optically using scatterometry performed on a Woollam V-Vase spectroscopic ellipsometer. Transmittance of p-polarized light was collected at angles of incidence of $0^{\circ}-80^{\circ}$ and at each angle of incidence the scattered transmittance at angles from $-1^{\circ}$ to $+1^{\circ}$ from direct were measured over wavelengths from 200-1100 $\mathrm{nm}$. The transmittance values were then weighted by the spectral response of a c-Si and a-Si:H PV cells to determine spectrally integrated transmittance values for each, and to allow for inter comparison of coatings. Because transmittance of p-polarized light is utilized, transmittance at non-normal incidence is not representative of actual sunlight transmittance due to polarization effects within the glass. However, because of the uniformity of the substrate used in this study, non-normal transmittance values, normalized by a glass sample at the same angle of incidence, can be considered representative of the relative transmittance of sunlight.

\subsection{Measurement of contact angle and $C A H$}

Measurement of contact angle was performed utilizing imaging techniques on coated glass plates. Sessile drop contact angle tests were performed on a level surface and digital photographs were taken of the plane normal to the surface of the coated plate. The contact angle was then measured utilizing image analysis techniques as the angle between the liquid/solid and liquid/gas boundaries, three independent tests were performed for each surface.

The contact angle hysteresis was measured as the difference between the advancing and receding contact angle of a sliding droplet. The test was performed by setting a droplet on a horizontal coated plate. This plate was tilted slowly until the drop began to slide along the surface, at which point the camera shutter was activated. The advanceing and receding contact angles were then measured using image analysis. Similarly to the sessile drop tests, three independent trials were performed for each surface.

\subsection{Time to clear from snowfall}

The measurement of the Time To Clear (TTC) a module from snowfall is used as a comparison of snow shedding effectiveness, which does not rely explicitly on the efficiency of the module over long term testing. This is because the methodology relies on the performance of a module relative to its own historical performance, rather than the absolute performance of the module. In order to accomplish this the coating effectiveness is defined by the time taken to completely clear a coated module from snowfall compared to an identical uncoated module at the same angle. In order to quantify the time taken for the modules to clear the following automated methodology was utilized:

1. The regression analysis developed in [25] was used to create synthetic days, removing the effects of snowfall on the modules.

2. Identify anchor points where the following conditions are met 
Preprint of: Rob W. Andrews, Andrew Pollard, Joshua M. Pearce, A new method to determine the effects of hydrodynamic surface coatings on the snow shedding effectiveness of solar photovoltaic modules. Solar Energy Materials and Solar Cells 113 (2013) 7178. DOI: 10.1016/j.solmat.3063.Øinaż analysis of PV array

a. Snowfall is present

b. $\frac{I_{s c}(t)}{I_{s c}(t)} \ldots \frac{I_{s c}(t+20 \mathrm{~min})}{I_{s c}(t+20 \mathrm{~min})}<0.7$

c. $\hat{I_{s c}}-I_{s c}>I_{s c o} \frac{1}{10}$

d. $\mathrm{AM}<6$

3. Search backwards from the anchor point to find the beginning of when the snow began to shed

a. $G(t)<10 W / m^{2}$ (Morning)

OR

b. $\frac{I_{s c}(t)}{I_{s c}(t)}>0.85$ (Point before daytime snowfall accumulation)

4. Search forwards from the anchor point to find where the snow stopped shedding

a. $\frac{I_{s c}(t)}{I_{s c}(t)} \ldots \frac{I_{s c}(t+20 \mathrm{~min})}{I_{s c}(t+20 \mathrm{~min})}>0.85$

Where $I_{s c}$ is the measured short-circuit current, $\hat{I_{s c}}$ is modelled short circuit current, $A M$ is Air Mass and $G(t)$ is the global irradiance at time $t$. The parameter $2 b$ can be tuned depending on the quality of the model fit, a value of 0.7 was chosen as it eliminates the possibility of other smaller loss mechanisms such as soiling or spectral mismatch from being considered a snow loss. Parameter $2 c$ sets a low threshold on the absolute difference which can be attributed to snowfall losses. This parameter is necessary to eliminate periods during cloudy, low-irradiance days where model relative error can be higher than the 0.7 threshold due to cloud variability, and the low absolute value of irradiance. The parameter for $3 b$ and $4 b$ is set to 0.85 , and this indicates the point where snow has been mostly cleared from the panel. The value of 0.85 was chosen due to the sensitivity of the model on cloudy days, where the model performance ratio may never reach 1 . Thus, 0.85 provided an acceptable balance of effective time to clear determination and realistic model performance.

It should be noted that in this study $I_{s c}$ and $\hat{I_{s c}}$ are used for snow shedding determination. However, the same methodology can be used with power outputs, $P_{m p}$ and $\hat{P_{m p}}$.

\subsection{Image analysis of $P V$ array}

In order to visualise the effects of surface coatings on the shedding patterns of modules, timelapse photography was utilized to capture a time series of images of each module. Photographs of the entire test array were taken at five minute intervals over the two years of operation. Each image was aligned using a luminance optimization algorithm [26] to a baseline image to reduce the effects of slight camera drift over time. The image was then thresholded using an Otsu adaptive algorithm [27] which identified snowcovered areas on the module array. Each module was then identified in the image and an individual image of snow distribution on each module for every timestep was developed. Each image pixel was then summed over the shedding period in order to create probability plots, which demonstrate the duration that snow existed on portions of a module over the entire shedding event. These probability plots can lead to insights into the variation in shedding mechanisms for varying coatings and meteorological conditions. 
Preprint of: Rob W. Andrews, Andrew Pollard, Joshua M. Pearce, A new method to determine the effects of hydrodynamic surface coatings on the snow shedding effectiveness of solar photovoltaic modules. Solar Energy Materials and Solar Cells 113 (2013) 7178. DOI: 10.1016/j.solmat.2013.01.032

\section{Results and Analysis}

The coatings used in the study were characterized by the sessile drop contact angle, contact angle hysteresis and spectral transmissivity; a summary of the results is given in Table 2 .

Table 2: Hydrodynamic and optical properties of coatings. All transmittance values are taken at normal incidence.

\begin{tabular}{cccccc} 
Coating & $\begin{array}{c}\text { Sessile drop } \\
\text { Contact angle }\end{array}$ & $\frac{\theta_{a d v}}{\theta_{r e c}}$ & CAH & $\begin{array}{c}\text { c-Si } \\
\text { transmittance }\end{array}$ & $\begin{array}{c}\text { a-Si:H weighted } \\
\text { transmittance }\end{array}$ \\
\hline \hline hy & $18.3^{\circ}$ & $\frac{42^{\circ}}{8^{\circ}}$ & $34^{\circ}$ & $90.0 \%$ & $89.9 \%$ \\
ho1 & $104^{\circ}$ & $\frac{119^{\circ}}{70^{\circ}}$ & $49^{\circ}$ & $90.9 \%$ & $90.9 \%$ \\
ho2 & $107^{\circ}$ & $\frac{124^{\circ}}{62^{\circ}}$ & $38^{\circ}$ & $90.7 \%$ & $90.7 \%$ \\
ho3 & $100^{\circ}$ & $\frac{112^{\circ}}{74^{\circ}}$ & $62^{\circ}$ & $90.0 \%$ & $89.7 \%$ \\
Bare & $39^{\circ}$ & $\frac{50^{\circ}}{10^{\circ}}$ & $40^{\circ}$ & $90.7 \%$ & $90.7 \%$ \\
Glass & & & & &
\end{tabular}

\subsection{Optical Effects of Surface Coatings}

The optical effects of the various surface coatings was investigated to determine their possible effects on PV energy yield.

A representative graph that illustrates the response of coated flat glass transmissivity to angle of incidence and scatter angle is shown in Figure 2. A similar graph for prismatic glass is shown in Figure 3 where it can be seen that there is a significantly higher degree of scatter from prismatic glass compared to standard glass. Because the elipsometer utilizes a colimating tube, it rejects scattered light, and therefore the transmissivity values of prismatic glass cannot be taken as representative. However the relative constant response at varying degrees of scatter is representative of a large amount of scattering.

Scatterometry results are provided in Figure 4. It is clear that all flat glass coatings exhibit similar scatter angle responses to a plain glass sample, which indicates that there are no significant light scattering effects of the coatings. The angle of incidence response did differ slightly from the plain glass samples at high angles of incidence as shown in Figure 5. The coatings ho2 and hy increase the reflectivity of the glass at high angles of incidence. 
Preprint of: Rob W. Andrews, Andrew Pollard, Joshua M. Pearce, A new method to determine the effects of hydrodynamic surface coatings on the snow shedding effectiveness of solar photovoltaic modules. Solar Energy Materials and Solar Cells 113 (2013) 7178. DOI: 10.1016/j.solmat.2013.412038now Shedding effects

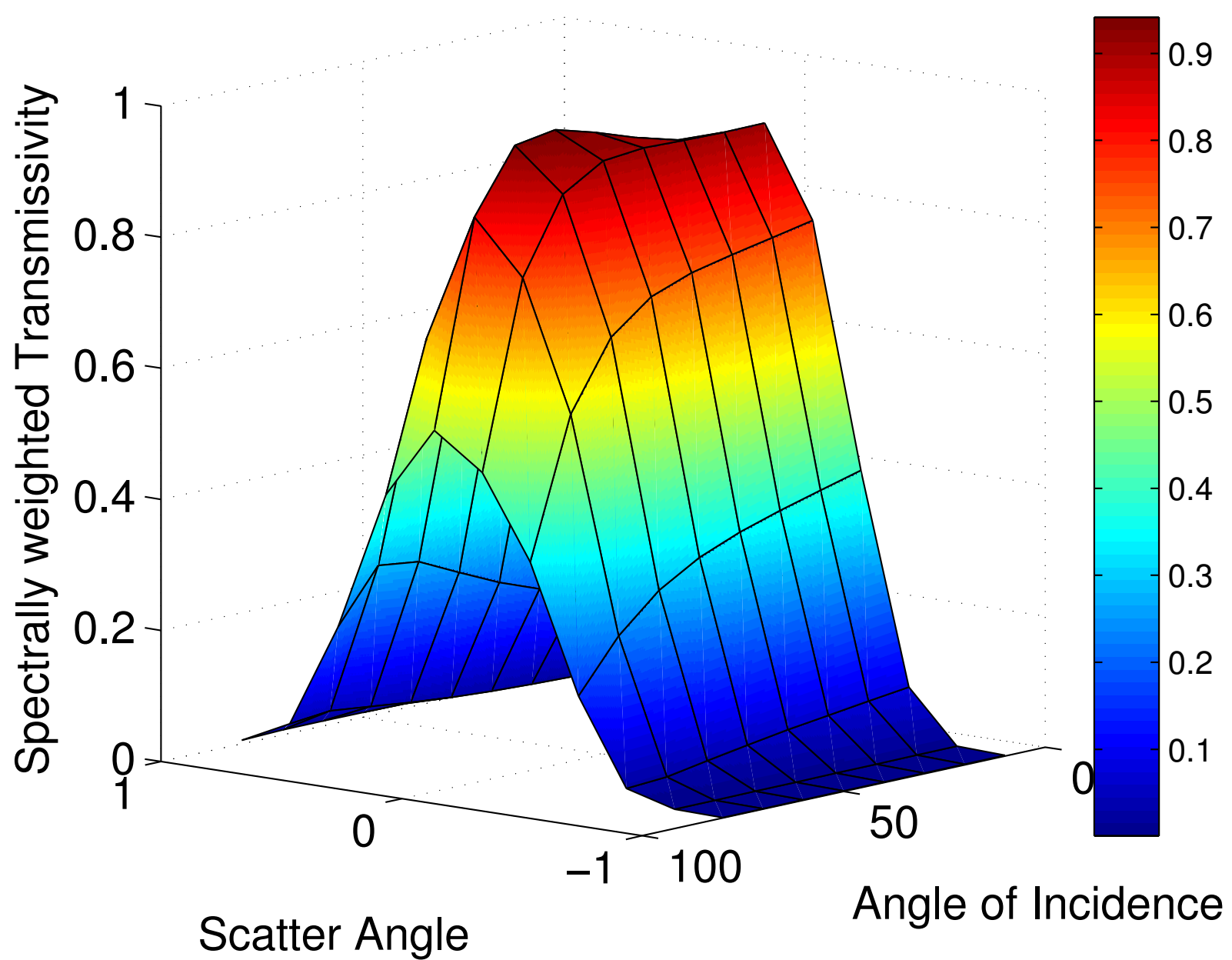

Figure 2: A scatterometry plot showing the spectrally-weighted transmissivity of coating ho1 as a function of scatter angle and angle of incidence. This surface is representative of all hydrodynamic coatings used in the study

\subsection{Snow Shedding effects}

Figure 6 shows the total time that a module is covered with snow, normalized by the total time the control panel at that angle was covered. This provides a measure of the snow shedding efficiency over the two winters of study, and it can be seen that coatings do not provide a predictable net benefit in keeping panels cleared from snow, as the coated panels were generally covered for longer periods than the uncoated modules. It can also be seen in Figure 6 that in some cases the application of a coating can have a large detrimental effect on snow shedding performance.

At $60^{\circ}$, Figure 6 shows that most coatings did improve the snow shedding effectiveness. It is likely that the greater shear forces between glass and snow at this higher angle increase the effect of a potential decrease in surface friction due to the surface coatings. It should be noted however that previous studies [3] 
Preprint of: Rob W. Andrews, Andrew Pollard, Joshua M. Pearce, A new method to determine the effects of hydrodynamic surface coatings on the snow shedding effectiveness of solar photovoltaic modules. Solar Energy Materials and Solar Cells 113 (2013) 7178. DOI: 10.1016/j.solmat.2013.412038now Shedding effects

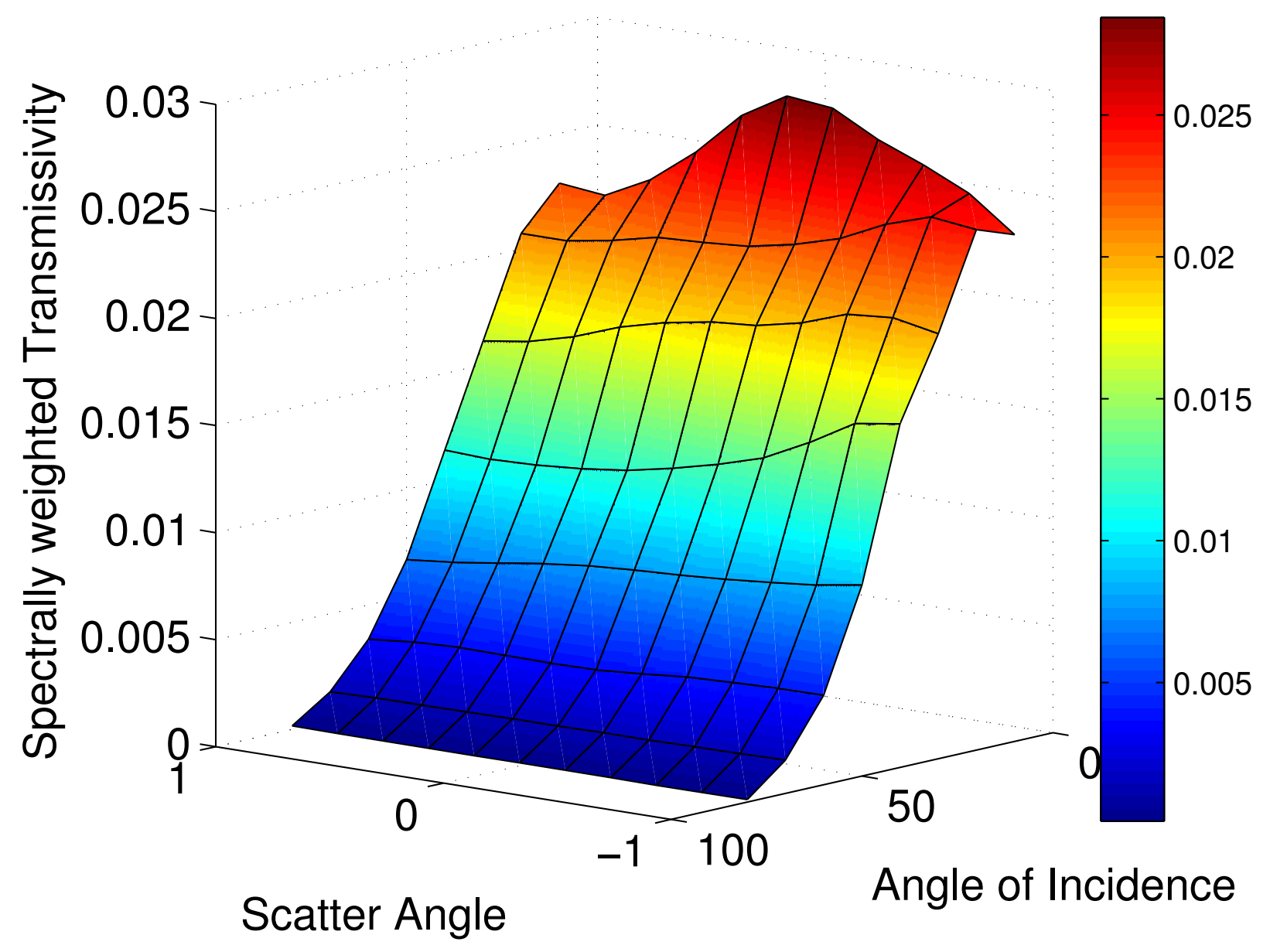

Figure 3: A scatterometry plot showing the spectrally-weighted transmissivity of prismatic glass as a function of scatter angle and angle of incidence. In this case, the transmissivity values cannot be taken as representative due to the effects of the collimating tube.

have shown that losses due to snowfall are already relatively low compared to those at shallower angles, and therefore improved clearance at this angle is not as beneficial to PV energy yield.

A detailed view of the shedding events provided in Figures 7- 10, show the normalized Time To Clear (TTC) correlated to the average temperature and relative humidity over a snow shedding event for all tilt angles. A snow shedding event is defined as the time when electrical losses are apparent due to snow coverage. In some cases, not all panels in a row experienced the start of a snow shedding events. For example, this happened in cases where modules were not all able to clear before another snow event occurred, which obscured all panels in a row. In this case the shedding time for the panel, which cleared fully and was re-covered, is not shown in the scatter charts. 
Preprint of: Rob W. Andrews, Andrew Pollard, Joshua M. Pearce, A new method to determine the effects of hydrodynamic surface coatings on the snow shedding effectiveness of solar photovoltaic modules. Solar Energy Materials and Solar Cells 113 (2013) 7178. DOI: 10.1016/j.solmat.2013.412038now Shedding effects

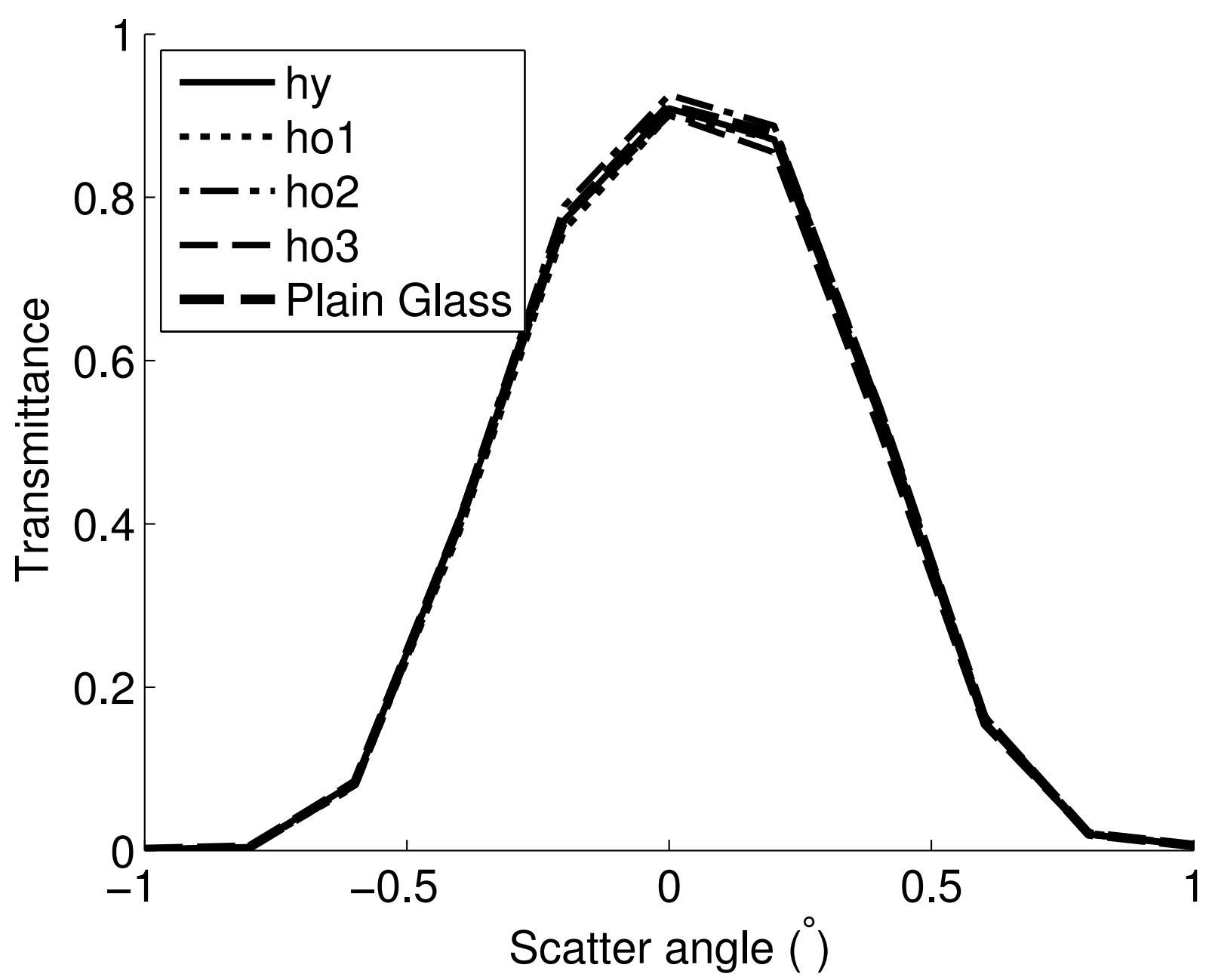

Figure 4: Absolute transmittances for the coatings in the study at $10^{\circ} \mathrm{AOI}$ as a function of scatter angle. This shows that none of the coatings had significant light scattering effects.

Overlaid on each point in Figures 7- 10 is a depiction of the location of snow on the surface of the panel during the shedding event.The methodology for deriving these plots is given in section 3.6, and are essentially a summation of timelapse photographs which identify the presence of snow on the surface of a module, where lighter colours represent snow staying on the module for a longer period of time. Images which are entirely white indicate the module was fully covered and released all snow in less than the 5 minute intervals between photographs. Some images that are largely dark represent periods where a small amount of snow, usually along the bottom edge of the module, hindered its performance. It should be noted that not all shedding events had recoverable time series photographs, and therefore not all points are correlated to a probability plot.

It can be seen from these plots that there are no clearly defined trends for clearance times as a function 
Preprint of: Rob W. Andrews, Andrew Pollard, Joshua M. Pearce, A new method to determine the effects of hydrodynamic surface coatings on the snow shedding effectiveness of solar photovoltaic modules. Solar Energy Materials and Solar Cells 113 (2013) 7178. DOI: 10.1016/j.solmat.2013.01.032

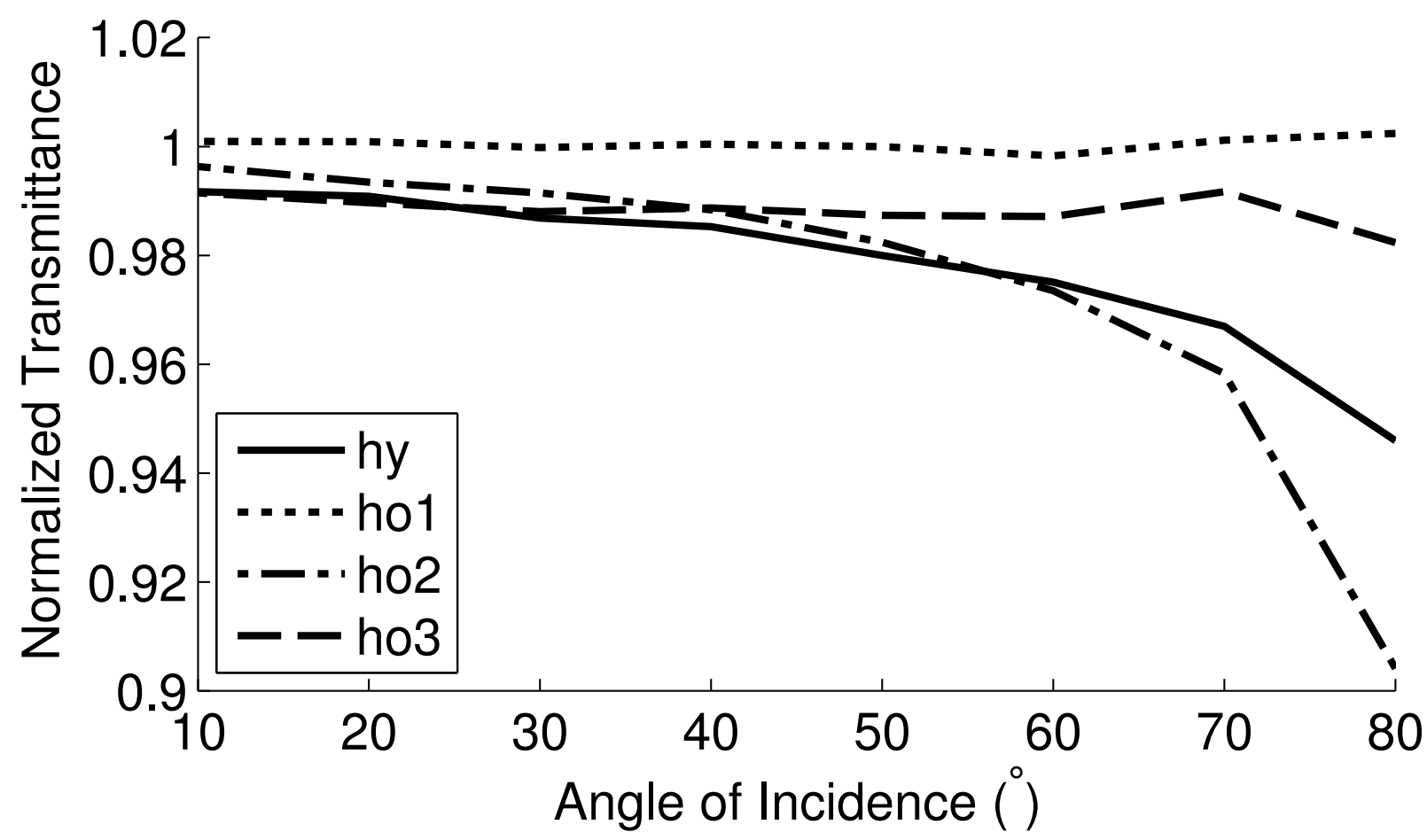

Figure 5: A comparison of transmittances for the coatings in the study as a function of AOI, normalized relative to a plain glass response. It can be seen that coatings hy and ho2 have a much higher reflectivity than glass at a large AOI.

of module temperature(Figure 7 and 9) or atmospheric relative humidity(Figure 8 and 10). Thus, it can be seen that the effects of the hydrodynamic coatings used in the current study on PV snow shedding times are not easily predictable based on the measured meteorological factors. However, in some cases there can be minor advantages to the application of some surface treatments, which appear to improve the mobility of the obscuring snow on the module and promotes shedding of the snow pack.

\section{Future work}

From this study it has been seen that the use of the hydrodynamic surface treatments with a $\mathrm{CAH}$ of $62^{\circ}$ to $34^{\circ}$ utilized in this experiment can have some minor positive effects on the snow shedding efficiency of a PV module, however in most conditions they can have a detrimental effect on snow clearing performance. There have, however, been studies showing that the use of superhydrophobic coatings can improve snow shedding effectiveness [22], and these coatings should be tested for their applicability as a snow shedding surface coating. 
Preprint of: Rob W. Andrews, Andrew Pollard, Joshua M. Pearce, A new method to determine the effects of hydrodynamic surface coatings on the snow shedding effectiveness of solar photovoltaic modules. Solar Energy Materials and Solar Cells 113 (2013) 7178. DOI: 10.1016/j.solmat.2013.01.032

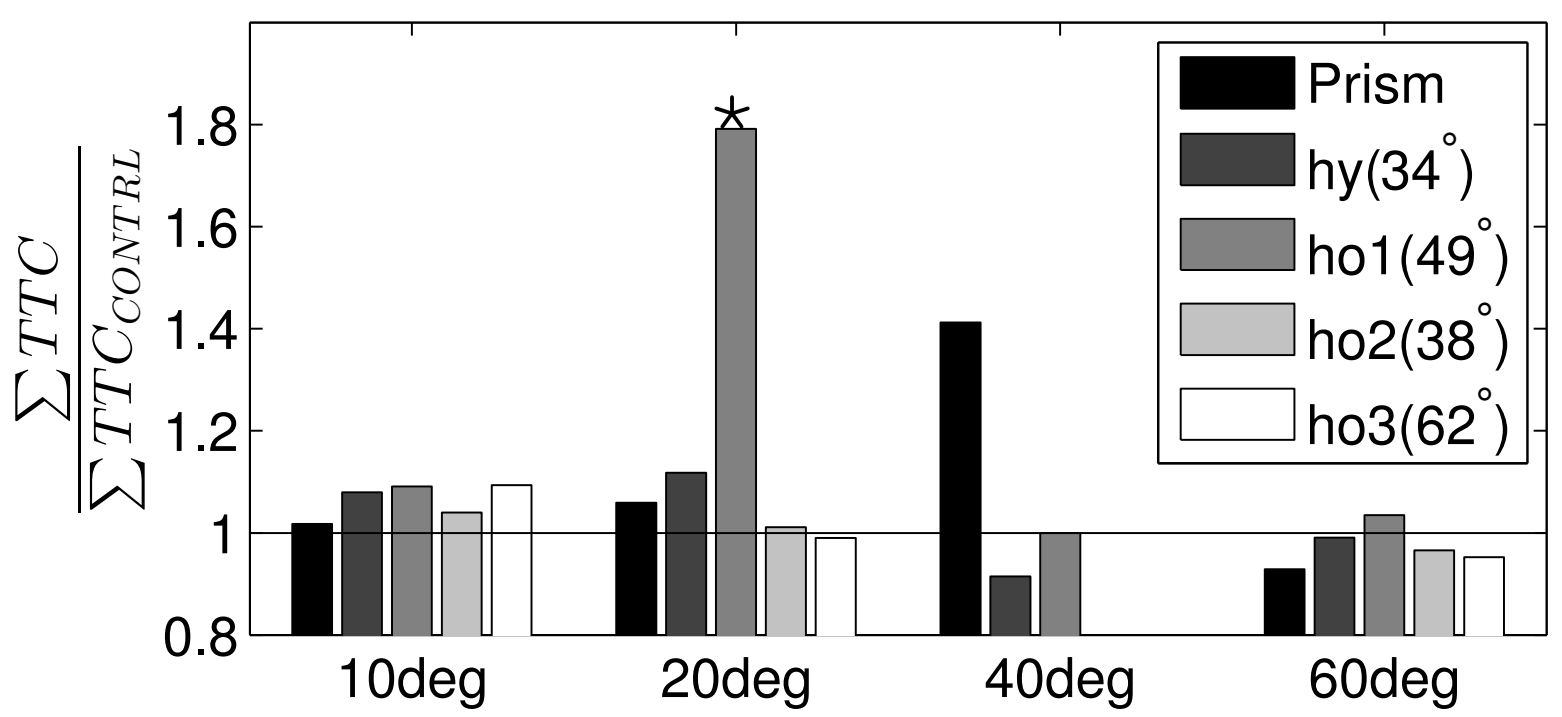

Figure 6: The total time a module was covered with snow, normalized by the total covered time of the control module. Numbers in brackets is the contact angle hysteresis of the coating. Note that coating ho1 at $20^{\circ}$ (marked by an asterisk) only contains data from one winter, and the remainder of points contains data from both winters.

Overall, this study has shown that snow shedding from glass surfaces is a complex process which depends on multiple variables, not all of which were controlled in this study. In order to better understand this process, a more controlled laboratory experiment should be undertaken in order to better isolate the factors that effect snow shedding efficiency on glass sheets, which could lead to the development of more effective coatings or processes to assist the clearance of snowfall.

\section{Conclusions}

This paper has developed a new methodology to determine the relative effectiveness of obstruction clearing from PV modules, which does not include external effects of power degradation over time. This methodology can be utilized to expand this study to investigate other methods of snow clearing on PV modules.

To validate this methodology, here a study has been undertaken that investigated the effectiveness of using hydrodynamic surface coatings to improve the shedding effectiveness of commercial PV modules. It was found that in aggregate there are no advantages to the use of hydrodynamic coatings for snow clearing from PV modules; however an improvement was seen in certain cases and coatings. In addition, appears that there was not a clear correlation between shedding effectiveness and the meteorological factors investigated (relative humidity and module temperature). Overall this study shows that the use of the tested hydrodynamic coatings does not provide appreciable benefits for the clearing of snowfall from PV systems. 
Preprint of: Rob W. Andrews, Andrew Pollard, Joshua M. Pearce, A new method to determine the effects of hydrodynamic surface coatings on the snow shedding effectiveness of solar photovoltaic modules. Solar Energy Materials and Solar Cells 113 (2013) 7178. DOI: 10.1016/j.solmat.2013.01.032

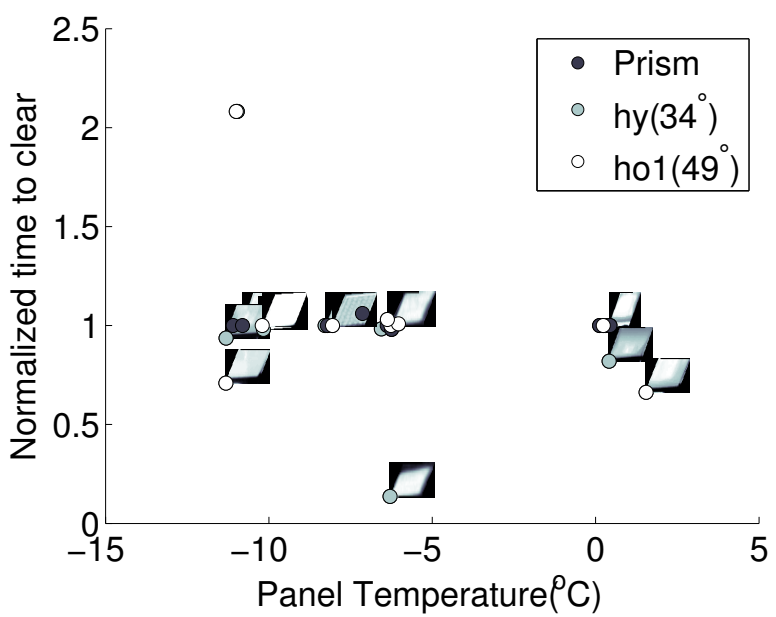

(a) $10^{\circ}$

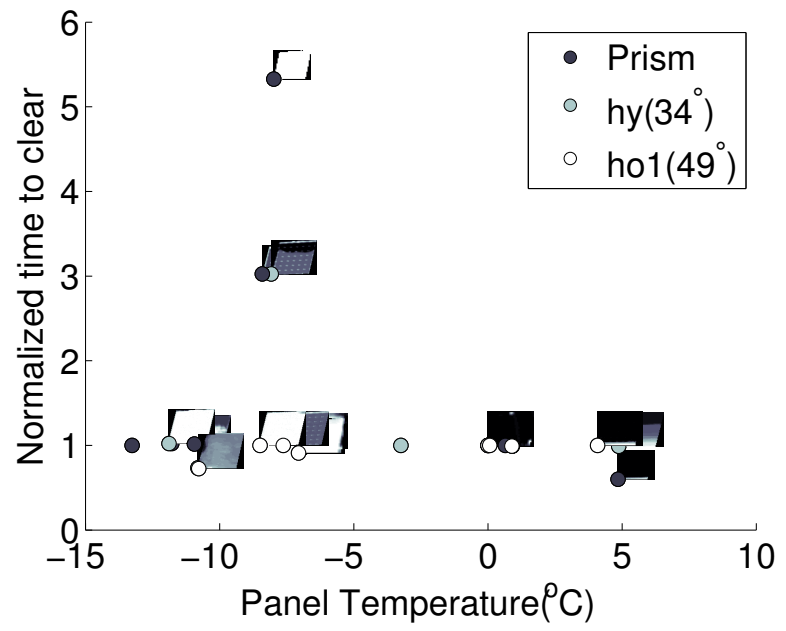

(c) $40^{\circ}$

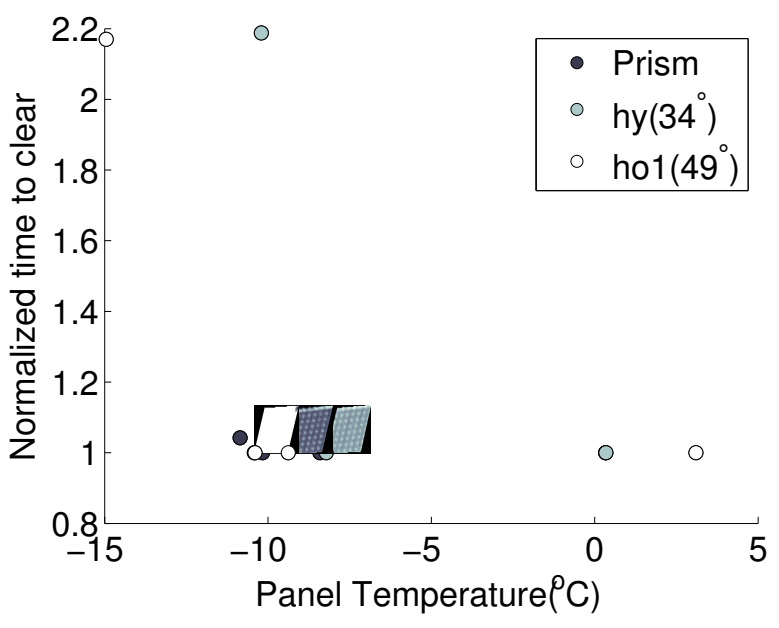

(b) $20^{\circ}$

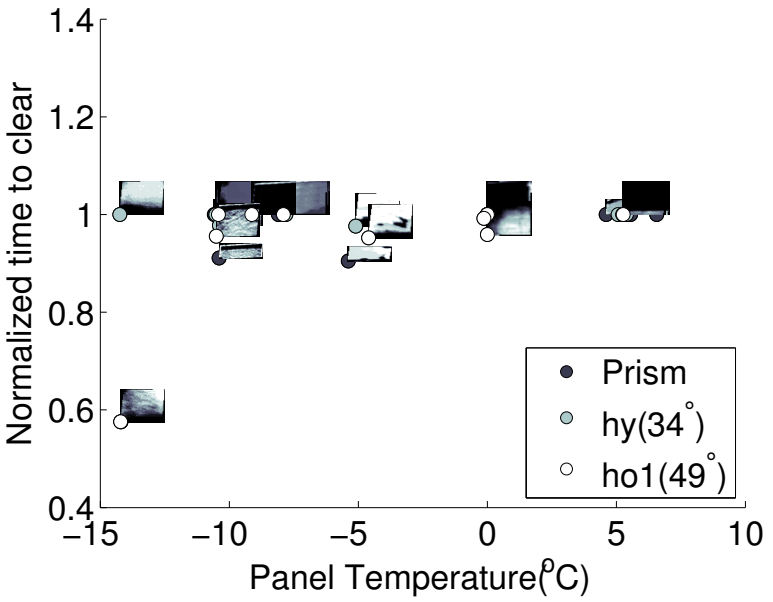

(d) $60^{\circ}$

Figure 7: Time to clear snow on c-Si modules normalized by the control as a function of temperature at tilt angles (a) $10^{\circ}$ (b) $20^{\circ}$ (c) $30^{\circ}$ (d) $40^{\circ}$. Where available, contours showing the locations of snow on the module during the shedding event are overlaid on the plot.

\section{Acknowledgements}

The authors would like to acknowledge the support of the Sustainable Energy Applied Research Centre at St. Lawrence College in addition to support from the Natural Sciences and Engineering Research Council of Canada and a Social Sciences and Humanities Research Council Strategic Research Grant on Environmental Issues. In addition, the support of the on-line communities for both Matlab and IATEX. 
Preprint of: Rob W. Andrews, Andrew Pollard, Joshua M. Pearce, A new method to determine the effects of hydrodynamic surface coatings on the snow shedding effectiveness of solar photovoltaic modules. Solar Energy Materials and Solar Cells 113 (2013) 7178. DOI: 10.1016/j.solmat.2013.01.032

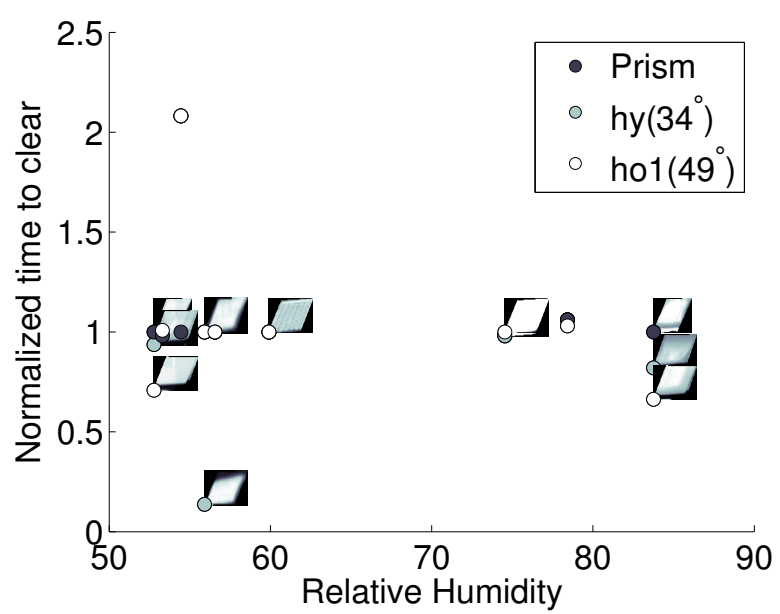

(a) $10^{\circ}$

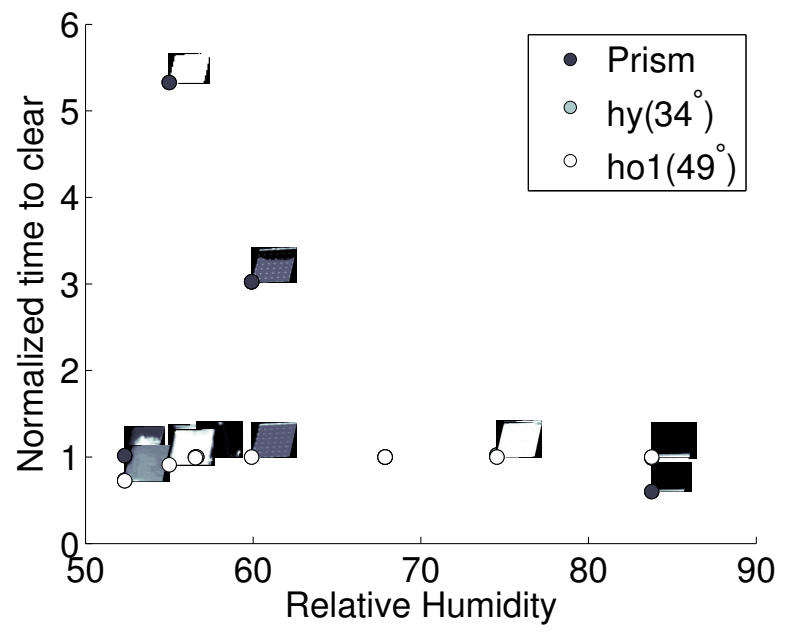

(c) $40^{\circ}$

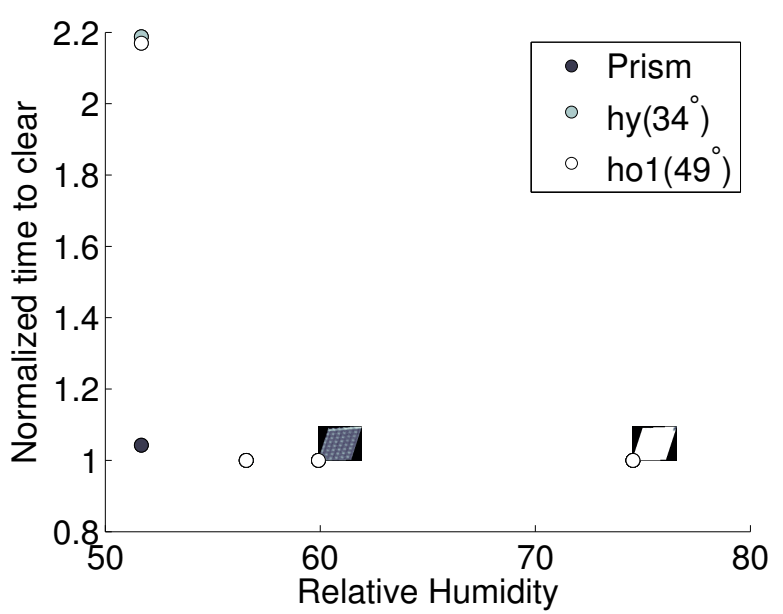

(b) $20^{\circ}$

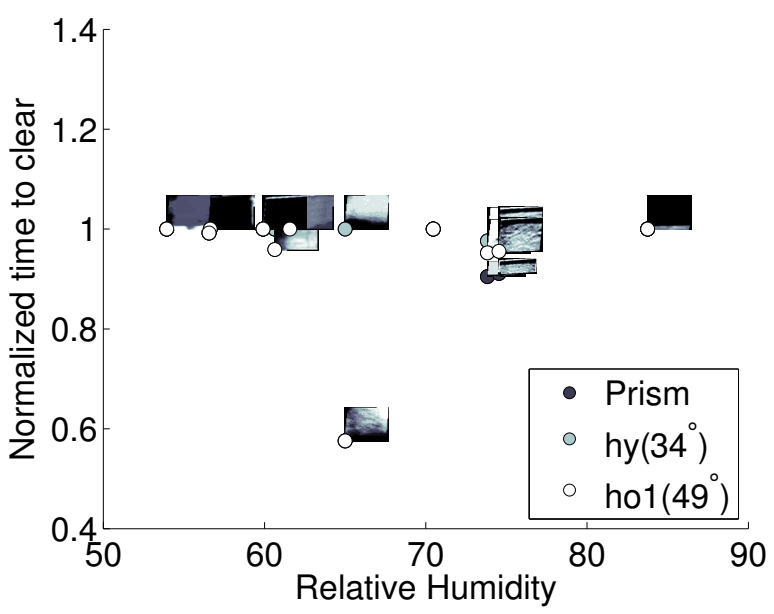

(d) $60^{\circ}$

Figure 8: Time to clear snow on c-Si modules normalized by the control as a function of Relative Humidity at tilt angles (a)10 ${ }^{\circ}$ (b) $20^{\circ}$ (c) $30^{\circ}$ (d) $40^{\circ}$. Where available, contours showing the locations of snow on the module during the shedding event are overlaid on the plot.

\section{References}

[1] K. Branker, J. Pathak, J. M. Pearce, A review of solar photovoltaic levelized cost of electricity, Renewable \& Sustainable Energy Reviews 15 (2011) 4470-4482.

[2] T. Townsend, L. Powers, Photovoltaics and snow: An update from two winters of measurements in the sierra, in: , Conference Record of the 37th IEEE Photovoltaic Specialists Conference, IEEE, 2011.

[3] Rob W. Andrews, Joshua M. Pearce, Andrew Pollard, Effects of snowfall on the performance of PV systems, Solar energy Under Reveiw (2012).

[4] R. Andrews, J. M. Pearce, Prediction of energy effects on photovoltaic systems due to snowfall events, in: Conference Record of the 38th IEEE Photovoltaic Specialists Conference, IEEE, 2012. 
Preprint of: Rob W. Andrews, Andrew Pollard, Joshua M. Pearce, A new method to determine the effects of hydrodynamic surface coatings on the snow shedding effectiveness of solar photovoltaic modules. Solar Energy Materials and Solar Cells 113 (2013) 7178. DOI: 10.1016/j.solmat.2013.01.032

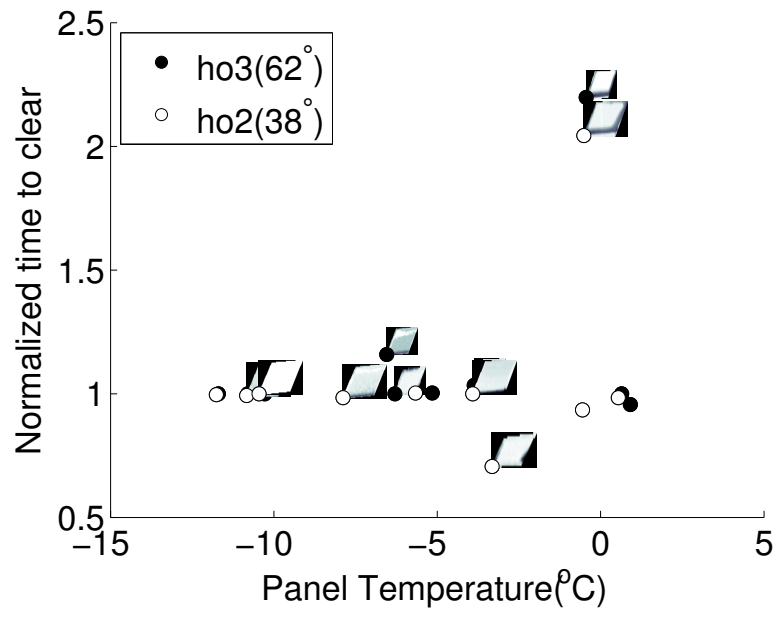

(a) $10^{\circ}$

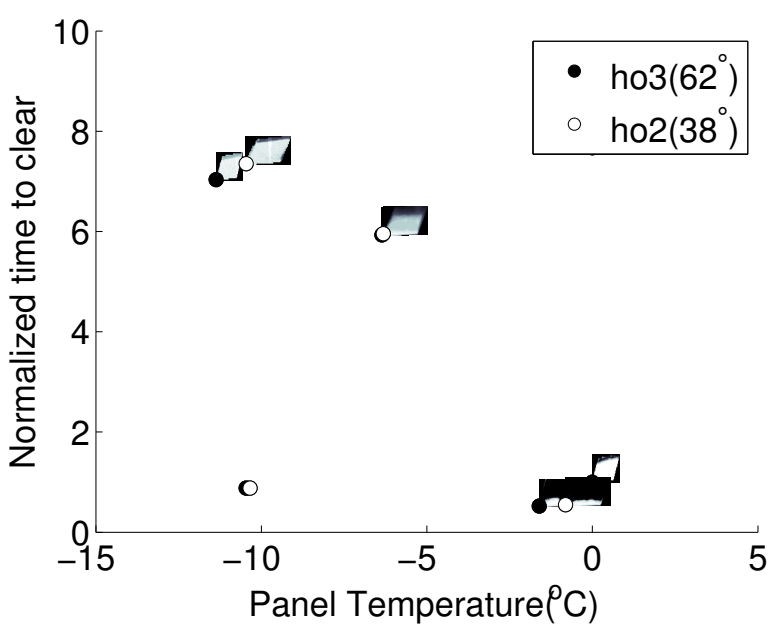

(b) $20^{\circ}$

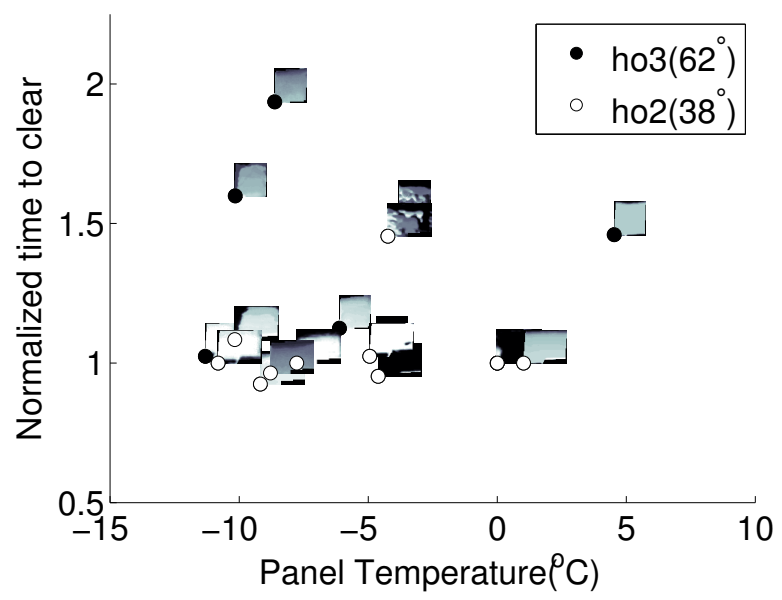

(c) $60^{\circ}$

Figure 9: Time to clear snow on a-Si:H modules normalized by the control as a function of temperature at tilt angles (a) $10^{\circ}$ (b) $20^{\circ}$ (c) $30^{\circ}$ (d) $40^{\circ}$. Where available, contours showing the locations of snow on the module during the shedding event are overlaid on the plot.

[5] S. Kulinich, M. Farzaneh, On ice-releasing properties of rough hydrophobic coatings, Cold Regions Science and Technology 65 (2011) 60-64.

[6] S. Kulinich, M. Farzaneh, Ice adhesion on super-hydrophobic surfaces, Applied Surface Science 255 (2009) 8153-8157.

[7] S. A. Kulinich, S. Farhadi, K. Nose, X. W. Du, Superhydrophobic surfaces: Are they really ice-repellent?, Langmuir 27 (2010) 25-29.

[8] S. Farhadi, M. Farzaneh, S. Kulinich, Anti-icing performance of superhydrophobic surfaces, Applied Surface Science 257 (2011) 6264-6269.

[9] S. A. Kulinich, M. Farzaneh, How wetting hysteresis influences ice adhesion strength on superhydrophobic surfaces, Langmuir 25 (2009) 8854-8856.

[10] A. J. Meuler, J. D. Smith, K. K. Varanasi, J. M. Mabry, G. H. McKinley, R. E. Cohen, Relationships between water 
Preprint of: Rob W. Andrews, Andrew Pollard, Joshua M. Pearce, A new method to determine the effects of hydrodynamic surface coatings on the snow shedding effectiveness of solar photovoltaic modules. Solar Energy Materials and Solar Cells 113 (2013) 7178. DOI: 10.1016/j.solmat.2013.01.032

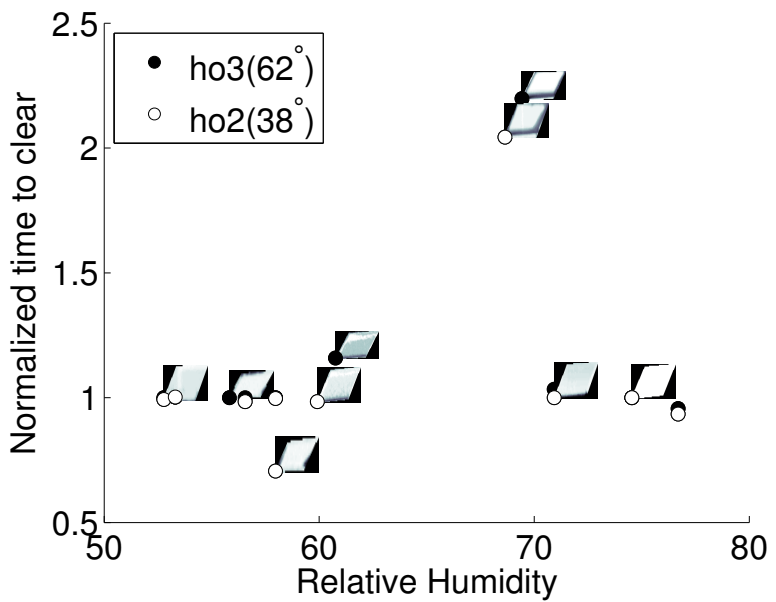

(a) $10^{\circ}$

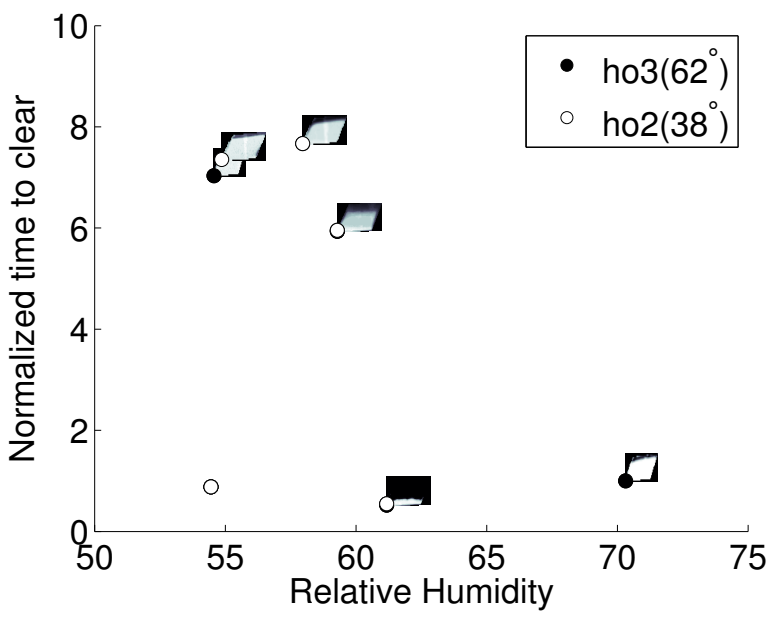

(b) $20^{\circ}$

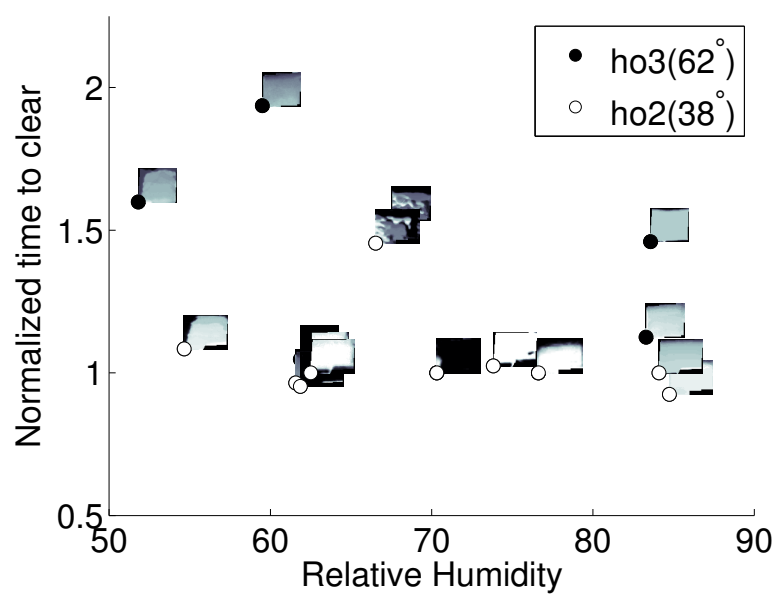

(c) $60^{\circ}$

Figure 10: Time to clear snow on a-Si:H modules normalized by the control as a function of temperature at tilt angles (a) $10^{\circ}$ (b) $20^{\circ}$ (c) $30^{\circ}$ (d) $40^{\circ}$. Where available, contours showing the locations of snow on the module during the shedding event are overlaid on the plot.

wettability and ice adhesion, ACS Applied Materials \& Interfaces 2 (2010) 3100-3110.

[11] G. Becker, B. Schiebelserger, W. Weber, J. Schumacher, M. Zehner, G. Wortuba, C. Vodermayer, Energy yields of PV systems- comparison of simulation and reality., Valencia, Spain.

[12] B. L. Brench, Snow-covering effects on the power output of solar photovoltaic arrays, DOE DE-AC02-76ET20279 (1979).

[13] B. Marion, J. Adelstein, K. Boyle, H. Hayden, B. Hammond, T. Fletcher, B. Canada, D. Narang, A. Kimber, L. Mitchell, G. Rich, T. Townsend, Performance parameters for grid-connected PV systems, 31st IEEE Photovoltaics Specialists Conference and Exhibition (2005).

[14] M. M. D. Ross, Snow and ice accumulation on photovoltaic arrays: An assessment of the TN conseil passive melting technology, report\# EDRL 95-68 (TR), energy diversification research laboratory, CANMET, Natural Resources Canada, Varennes, September (1995). 
Preprint of: Rob W. Andrews, Andrew Pollard, Joshua M. Pearce, A new method to determine the effects of hydrodynamic surface coatings on the snow shedding effectiveness of solar photovoltaic modules. Solar Energy Materials and Solar Cells 113 (2013) 7178. DOI: 10.1016/j.solmat.2013.01.032

[15] H. Yoshio, S. Toshiyuki, T. Makoto, Snow fall on the photovoltaic array and snow sliding condition., Journal of Snow Engineering of Japan 15 (1999) 15-16.

[16] K. Yoshioka, T. Saitoh, T. Yamamura, Performance monitoring of a building-integrated photovoltaic system in an urban area, in: Photovoltaic Energy Conversion, 2003. Proceedings of 3rd World Conference on, volume 3, pp. 2362-2365 Vol.3.

[17] H. Wang, G. He, Q. Tian, Effects of nano-fluorocarbon coating on icing, Applied Surface Science 258 (2012) $7219-7224$.

[18] M. A. Sarshar, C. Swarctz, S. Hunter, J. Simpson, C. H. Choi, Superhyrdophobic surface properteis for anti-icing (2012).

[19] Z. Yuan, J. Bin, X. Wang, Q. Liu, D. Zhao, H. Chen, H. Jiang, Preparation and anti-icing property of a lotus-leaf-like superhydrophobic low-density polyethylene coating with low sliding angle, Polymer Engineering \& Science 52 (2012).

[20] L. Cao, A. K. Jones, V. K. Sikka, J. Wu, D. Gao, Anti-icing superhydrophobic coatings, Langmuir 25 (2009) $12444-12448$.

[21] C. Furmidge, Studies at phase interfaces. i. the sliding of liquid drops on solid surfaces and a theory for spray retention, Journal of Colloid Science 17 (1962) 309-324.

[22] KAKO Tetsuya, NAKAJIMA Akira, KATO Zenji, UEMATSU Keizo, WATANABE Toshiya, HASHIMOTO Kazuhito, Adhesion and sliding of snow on hydrophobic solid surface, Nippon seramikkusu kyokai gakujutsu ronbunshi 110 (2002) $186-192$.

[23] T. Kako, A. Nakajima, H. Irie, Z. Kato, K. Uematsu, T. Watanabe, K. Hashimoto, Adhesion and sliding of wet snow on a super-hydrophobic surface with hydrophilic channels, Journal of Materials Science 39 (2004) 547-555.

[24] J. M. Pearce, A. Babasola, R. Andrews, Open solar photovoltaic systems optimization, Proceedings of the 16th Annual National Collegiate Inventors and Innovators Alliance Conference, Open 2012 (2012).

[25] R. W. Andrews, A. Pollard, J. M. Pearce, Improved parametric empirical determination of module short circuit current for modelling and optimization of solar photovoltaic systems, Solar Energy 86 (2012) 2240-2254.

[26] M. Guizar-Sicairos, S. T. Thurman, J. R. Fienup, Efficient subpixel image registration algorithms, Optics Letters 33 (2008) 156-158.

[27] O. Nobuyuki, A threshold selection method from gray-level histograms, Systems, Man and Cybernetics, IEEE Transactions on 9 (1979) $62-66$. 